\begin{tabular}{ccc}
\hline & International Journal of Engineering \& Technology, 7 (2.32)(2018) 100-103 \\
SPC & Website: www.sciencepubco.com/index.php/IJET \\
Research paper & Jechnology \\
\hline
\end{tabular}

\title{
Study on Disaster Recovery in Cloud Environment
}

\author{
Dr. K.Ravindranath, N Raghupriya,P.Krishna Vamsi, ${ }^{4}$ D Sharath Kumar \\ Department of CSE, KL E F, Guntur, India. \\ *Corresponding author E-mail: ravindra_ist@kluniversity.in
}

\begin{abstract}
In Today's world information been produced in huge sum, which requires data recovery assistance. The cloud service providers give security to the client regardless of the possibility that systems are down, because of disaster. A lot of private information is produced which is put away in cloud. In this manner, the need for recovery of data services are developing in an order and needs an advancement of an well-organized powerful data rescue strategies, when information is lost in a disaster. The motivation behind recovery strategy to support client from gathering data from any alternate server whenever that server lost information and incapable to provide information to the client. On the way to accomplish the reason, numerous diverse procedures have been proposed. In circumstances like Flood, Fire, seismic tremors or any equipment glitch or any accidental deletion of information may never again remain accessible. The target of this recovery is to condense the intense data recovery procedures that are utilized as a part of cloud computing area. It additionally describes the cloud-based disaster recovery stages and recognize open issues identified with disaster recovery.
\end{abstract}

Keywords: Disaster, Recovery, Cloud, Services, Information..

\section{Introduction}

Cloud Computing is storing and accessing the data over the internet instead of our own computer hardware also web based process where organizations are unified with distribution of resources. Cloud has servers where customer is associated with store server and can store information through web and can get to information from anyplace. We can say it as actual communication system. Distributed computing ends up noticeably well known for expansive scale registering in this day because of its capacity to share all around appropriated assets. Also many SMEs today are dependent on net. Business stability plays a vigorous necessity of maximum big business, and a unexpected interruption can straightly effect corporate purposes affecting substantial losses of financial, commercial fame and retail share. Most of the organizations may find problematic to identify disaster. The causes of disasters can either be manmade or natural which leads to huge loss of data. Some of the causes of data is power failure, earthquakes, fires, theft, and floods. When a disaster occurs the organization need to secure the data from these attacks from the data loss. To overcome the disaster events we have some recovery techniques to recover the data. The cloud computing provides an affordable DRPs for small or medium sized businesses. Backing up, traditional method is set for the disaster recovery. For business continuity many organizations developed several recovery techniques that are required. A documented disaster recovery process should be maintained by every organization and should test that process every year. Every organization's should set the targets plainly, and assess possible calamity recuperation intends to pick the DRP that would be ideal.

\section{Related Work}

Various researches have been carried out on cloud disaster recovery different approaches and techniques. Among them few techniques are presented here.

\subsection{Disaster Recovery as a Service in Cloud Computing: [7]'}

Disaster recovery as a service, classification of cloud utilized to shield the application or information after a characteristic or human interruption or administration interruption in a unique area by empowering a full recuperation in the cloud. DRaaS is the replication and encouraging of physical or virtual servers by an outsider to give failover if there should be an occurrence of a man-made or consistent disaster. Author Wood Proposed a new cloud facility model, disaster recovery as a cloud service, for site applications which illustrated that information backup built on high performance cloud resources can greatly reduce the price of data disaster. DRaaS contrasts from cloud-based reinforcement benefits by securing information and giving standby processing limit on request to encourage more fast application recovery. DRaaS limit is conveyed in a cloud so recuperation resources are paid for when they are used, making it more capable than an ordinary catastrophe restoration warm site or hot site where the recuperation resources must continue running consistently.

\subsection{Cloud standby deployment for disaster recovery in} cloud: [1]'

Utilizing completely operational standby locales with occasionally refreshed standby framework is anoutstandingwaytodeal against disasters. Setting up and keeping up a second data center is, in any case, expensive. A model driven deployment model is meant for disaster recovery. This strategy consists of an indistinguishable explanation language and the process is created on the same depiction language.

\subsection{Efficient and Secured Approach for Faster Data Availability and Restoration in Disaster Cloud Data- Management: [3]'}

In the Account setup, the client registers itself to CSP's to use the services. The work depends on File System thus on registration of 
three directories is made to fulfill. In data transferring stages the information transferred through the client it is encoded then shipped towards the bulk server. The data is formerly backup to the server where its again encrypted and put away in another protected index for managing disaster issues. In the Data downloading stage, when client needs the information it demands the server at thatpoint wheretwo cases, one the minute the information can be accessible formerly the demand through the clientsatisfied. One more case, whenever disaster happened then the rebuilding procedure happens through utilizing reinforcement. In this the client appeal is sent to alternate server and it reacts to the client immediately.

\subsection{Back up and disaster recovery system for HDFS [2]'}

Torecoveryourinformationincaseofany disaster, you should first have your information periodicallymoveddownfromyour framework. Moving down of information shouldbepossiblethroughdifferentsystems and your decision will be founded on the RPO that will suit your business needs. However if your data is generally static with a low recurrence of changes, you can decide on periodic incremental backup.

\subsection{Discovering Disaster Recovery Parameters in an Enterprise Application: [10]'}

Deals with unexpected disturbances that causes vast economic and fame damages to the administrations. This study is towards identifying parameters that impact the catastrophe recovery. These parameters are Controlling and Authorized necessities, Credentials of right set of shareholders, Disk storage construction and purpose of restoration direction of critical assistance and identifying parameters.

\section{Traditional Disaster Recovery}

\subsection{Tier 0: No offsite data}

Offsite is backup process, where we can secure data in the event of disaster in magnetic tapes, removable disks. No offsite data can be explained as the no disaster recovery strategy and no protected information. That means documents recovery might takes weeks besides can be unsuccessful.

\subsection{Tier 1: Backup with no host site}

Back up with no hot site means the data is backed up by offsite but not hot site. To get the data that is stored would take time. No redundant servers of their own time taken to progress towards trace and organize the administrations. The associations must be set up to acknowledge numerous days to weeks, yet the reinforcements are secured off-site. In any case, this level is undersupply of the frameworks for which to reestablish information.

\subsection{Tier 2: Data backup with hot site}

It means every association should preserve data standby servers as well as hot site. By having a hot reinforcement location we can run applications at standby servers when disaster occurs. This hot site backup determination results in the requirement to re-form some hours or days to recover information, but recovery period can be anticipated.

\subsection{Tier 3: Electronic vaulting}

As an alternative of backupphysicallylike tapes it offers technique called electronic vaulting, files are backed up and electrically transmitted to a secure storage location contains high-speed circuit communication, a few frame of channel expansion hardware and remote sites. As hot location reinforcement is costly it is way better to get to it by net through this electronic vault.

\subsection{Tier 4: Point in time copies}

This type of solutions requires larger information exchange and quicker recovery than clients of inferior tiers. PIT means every association preserves and uses appropriate this holdup of critical information which is web reachable to backup site.

\subsection{Tier 5: Transaction integrity}

The businesses that use this type of solutions are consistency of data between the production data sites and the recovery data sites. Such that any records damage can be done. This transaction integrity performance relies on the application which is in use.

\subsection{Tier 6: Zero or near data loss}

$\mathrm{BCP}$ maintains the data concurrency industries by means of slight or no allowance intended for information loss and wants to bring back information to tenders in a fast way. It doesn't depend on the applications to provide data consistency. It requires disk mirroring and provides many synchronous in addition asynchronous results for the storage retailers. It depends on amount of data and also sort of information exist on tape.

\subsection{Tier 7: Highly automated, business integrated so- lution}

It ensures consistency of data that which is agreed by minimal data loss solutions. It also provides the recovery of the appliance which is computerized and allows for renewal of systems such that applications becomes fast and consistent. In addition to that traditional data redundancy geographically, another method, requires data centers with well-equipped to stock data whenever it is backed up. For a faster recovery we need to organize some kind of hardware and software to geo-redundant localities to assure recovery time objective. Traditional recovery provides better RTO and RPO.

Virtualization ease the conventional disaster recovery through reducing the consistency by organizing the hardware arranged location which are used to recover. With virtualization, it can be possible to reduce the time needed to complete full restoration to lesser hours. The configuration of hardware on recovery spot must be identical to the primary place such that it can carry the entire traffic load by effected site. The RTO on virtual machine would be similar to the RTO on customary standby site configuration when the applications are booted from disasters.

\section{Disaster Recovery Requirements}

When a disaster occurs the main key features for an effective cloud are RTO and RPO. These are the two main factors of a disaster recovery or for the protection of the data. Both lead to choose an optimal data backup plan for an enterprise. It provides basis to identify and analyze the strategies in recovery plans.

\section{Recovery Point Objective}

The maximum period to recover the information after a disaster happens is called RPO. The necessity of this recovery point objective is that application data cant' be lost, also requires continuous synchronous replication. The acceptable data loss is allowed in some application, range sec to hours or a day. It recognizes the data that how much lost in the occurrence of disaster. The RPO is managed in such a method that how much the data is saved and backup. Daily offsite backups can sustain data failure locations with a week of loss of data. Every day offsite backup's reinforcements are better. Daily on-site backups sustain the production environment loss with a day loss of data. In addition to that replicating the transactions at the time of recovery after the loss of application. Hourly backups are enhanced.

A Network area storage or storage area network sustain damage of a distinct site excluding instances for records correction by no information loss. A grouped database can sustain the loss of specific storage devices without files loss. A database with multiple data 
hubs can sustain loss of some kind of separate data sites with no data loss.

\section{Recovery Time Objective}

RTO is the time duration between disasters till restoration of service which may take days also includes the intrusion detection. It prepares the essential servers at backup sites which lead to prepare the system which is broken at the time of execution. It recognizes downtime how much it can be acceptable at the time of disaster. By using the synchronous replication of application we can increase the disaster recovery performance. DR should have five requirements to have an effective performance and have to reduce RPO and RTO, should have a slight consequence on the regular process. Application must be returned to a regular state. Must assurance privacy and confidentiality.

\section{Disaster Recovery Plan}

Few components are executed for information reinforcement when disaster recuperation strategies are utilized. Backup locales can come from three distinctive sources like organizations master in providing disaster recuperation services, others areas claimed and operated by own organization and by a shared understanding with another organization to share information center offices in the occurrence of a disaster.

Hot Backup Site: It is very costly. Hot backup location works for the real time processes organizations. It acts like a secondary site to the primary. Here the loss of data is minimum such that we can restore the data.

Cool backup site: It is the least costly than hot back up site and don't include hardware deployment and doesn't take any back up. Before every operation is performed everything must be restored and delivered to the site.

Warm backup site: It is well equipped by hardware alignment arranged the secondary or backup location that established on the primary site.

DR in cloud is a cheaper service as compared to conventional disaster recuperation. It replicates physically or virtually and is flexible. Recovery strategies offer reliable for few working applications. It consists pre-fabricated selections for effective recovery surroundings counting security, system connectivity and server failover. Whenever disaster occurs we can back up and run applications on cloud till we get back up to main site.

Disaster recovery as a service which we can say free or pay on use offer. The construction of DRaaS is explained by three replicas:

From Cloud: when the essential application or information is in cloud and backup location is in reserved information center

In cloud: Both primary site and backup places present in cloud. To cloud: when the application lies in data center which is pf primary and backup or recovery location present in cloud.

The data is available to individual organization supervisor. Answers are pre-packaged services that deliver a standard DR. Failover to a cloud environment that you can buy on a pay-per-use basis with varying rates based upon your recovery point objective (RPO) and recovery time objective (RTO).

\section{Challenges Encounter In Cloud Disaster Re- covery}

\subsection{Dependency}

This is one of the impediments of cloud where clients has no regulation or control over data and their system. This makes customer to depend on CSP's.

\subsection{Cost}

The most important factor to choose DR as it is low cost. Cloud always provides cheaper way of mechanism at different cost.

\subsection{Detection of failure}

FD impacts on the framework downtime. So it is basic to recognize and report detection at the earliest opportunity for a quick and right DR.

\subsection{Security}

Disaster can be made by environment or human-made. Cyber terrorism is one of most human-made failures, can be refined because of some reasons.

\subsection{Data Storage}

Increase in usage of cloud in market and business it is necessity to store vast quantity of information on cloud established storages. In order to gratify applications and assurance the security of data, computing has to distribute nevertheless storage needs to remain unified. Therefore storage single point of failure and information loss is one of the challenges to store data in cloud.

\begin{tabular}{|l|l|l|}
\hline Challenges & Solutions & Techniques \\
\hline Dependency & Local backup & $\begin{array}{l}\text { Using a Linux box at the } \\
\text { customer premises }\end{array}$ \\
\hline Cost & Scale up/down & $\begin{array}{l}\text { Allocating resources to } \\
\text { high priority services. }\end{array}$ \\
\hline $\begin{array}{l}\text { Failure prediction } \\
\text { and detection }\end{array}$ & $\begin{array}{l}\text { Resource Management, } \\
\text { GRB(Geographical } \\
\text { redundancy and backup) }\end{array}$ & $\begin{array}{l}\text { Prediction and } \\
\text { replacement of risky } \\
\text { hardware } \\
\text { Using monitoring unit }\end{array}$ \\
\hline Security & $\begin{array}{l}\text { SDDB (secure distributed } \\
\text { data backup) }\end{array}$ & $\begin{array}{l}\text { Using encryption, } \\
\text { scrambling and shuffling } \\
\text { techniques }\end{array}$ \\
\hline Data storage & IPCS & $\begin{array}{l}\text { Using an inter private } \\
\text { cloud }\end{array}$ \\
\hline
\end{tabular}

\section{Open Issues and Future Directions}

It explains about the properties, connected solutions and the systems that are introduced. Moreover, some problems need effort for DR mechanism in the cloud. Some open and connected problems are discussed below in this section.

\subsection{Maximizing Resource Utilization}

We know in cloud the services are pay for what you use and the resources must be available at any time when needed of DR services is less, since the disasters are scarce. Thus, the income and utilization of DR Correlated Failures

If a disaster is occurred in an area, leads to huge interruption of services and accordingly many customers approaches CSP to recover the data. In this context, the servers can't be able to handle the clients. One main task in this instance is how to allocate clients between servers in such a way that they can minimize correlated failure risk. 


\subsection{Privacy and confidentiality}

The data centers which are of private companies would be a failover through cloud environment in the event of disaster. So one serious problem is that cloud should assure the confidentiality of data and privacy resources which were used for DR mechanisms. In addition to that the cloud must guarantee the application performance that wouldn't get affected by disasters occurred at other originalities.

\subsection{Disaster Monitoring}

The expected QoS should be delivered to firms by the failure tolerance. The faster disaster detection in primary site or backup spot clues to better RTO in the case of disaster. The main task is how the rank would be observed also disaster detection in initial stages.

\subsection{Resource Scheduling}

As we know that the cloud services are growing gradually, the complexity of infrastructures are also increasing. Thus, the resource scheduling is the main problem in the model cloud based environment. The unpredictable arrival rate of customers and also various disaster situations should be considered for cloud DR platforms. Therefore, for current DR platforms we require more efficient resource scheduling techniques.

\section{Conclusion}

The associations must recognize the possible happenings that can root disasters and assess that particular effect. They have to fix the goals undoubtedly, assess efficient disaster recovery strategies to pick the DRP that would be ideal. The paper analyses trade-offs included and displays rules for picking amongst the disaster recovery alternatives. The ideal disaster recovery arranging must contemplate the main parameters with the underlying cost, the rate of information exchanges, and the charge of information stockpiling. The association information requirements and its disaster recovery destinations should be considered. To assess the hazard, the sorts of disaster either normal or human-made must be recognized. The chance of a disaster event should be evaluated alongside the expenses of parallel failures. A suitable methodology for the cost assessment should be resolved to permit a quantifiable evaluation ofdynamic Disaster Recovery Plans (DRP) regarding the time required to re-establish the administration (related with RTO) and conceivable loss of information (related with RPO). This could control future advancement of the arrangement and maintenance of the DRP.

\section{References}

[1] Lenk, A., \& Pallas, F. (2013), Cloud Standby System and Quality Model, International Journal of Cloud Computing, 1(2), 48 - 59

[2] Alhazmi, O.H. (2015), Computer Aided Disaster Recovery Planning Tools (CADRP), International Journal of Computer Science \& Security (IJCSS), 9(3), 132-139.

[3] Yong, Z., Jie, C., Lei, L., Jin, L. (2014), The Design of Data Disaster Recovery of National Fundamantal Geographic Information System, The International Archives of the Photogrammetry, Remote Sensing and Spatial Information Sciences, Volume XL-4, 353 - 356.

[4] Khoshkholghi, M.A., Abdullah, A., Latip, R., Subramaniam, S., \& Othman, M. (2014), Disaster Recovery in Cloud Computing: A Survey, Computer and Information Science, 7(4), 39 - 54.

[5] Chervenak, A., Vellanki, V. \& Kurmas, Z. (1998), Protecting file systems: A survey of backup techniques, Joint NASA and IEEE Mass Storage Conference

[6] Cruz, R., \& Russel, D.V., (2003), Business Continuity Planning and Disaster Recovery Planning, The CISSP Prep Guide Gold Edition,indianapolis, Wiley Publishing, Inc., Indianapolis, Indiana, 377-408.

[7] Disaster Recovery Strategies with Tivoli Storage Management (2002), IBM, Second Edition

[8] Guster, D., \& Lee, O. F. (2011), Enhancing the Disaster Recovery Plan through Virtualization, Journal of Information Technology Research, 4(4)

[9] Jian-hua, Z., \& Nan, Z. (2011), Cloud Computing-based Data Storage and Disaster Recovery, IEEE International Conference on Future
Computer Science and Education (ICFCSE), 629-632, http://dx.doi.org/10.1109/ICFCSE.2011.157

[10] Kawaguchi, H. (2012), Study of Effective Cooperation Way between RA and BIA in Business Continuity Management, Proceedings of Japan Industrial Management Association, 302-303.

[11] Khoshkholghi, M.A., Abdullah, A., Latip, R., Subramaniam, S., \& Othman, M. (2014), Disaster Recovery in Cloud Computing: A Survey, Computer and Information Science, 7(4), 39 - 54

[12] Kumar, D., Gupta, V., Kapur, P.K. (2015), Assessment of Quality Factors in enterprise application integration, 4th International Conference on Reliability, Infocom Technologies and Optimization (ICRITO), (Trends \& Future Directions), IEEE, 10.1109/ICRITO.2015.7359352. 